\title{
EL CONCEPTO DE CONSUMIDOR EN EL ORDENAMIENTO JURÍDICO EUROPEO Y ESPAÑOL
}

\section{The concept of consumer in the European and Spanish law}

\author{
Henrry Sosa Olán* \\ Universidad Juárez Autónoma de Tabasco \\ México
}

RESUMEN: El presente trabajo tiene como objetivo demostrar cómo el concepto de "consumidor" ha sido uno de los caballos de batalla a nivel comunitario y en el ordenamiento jurídico español; prueba de ello son las diversas sentencias del Tribunal de Justicia de las Comunidades Europeas, en donde se ha excluido a las personas jurídicas que adquieren bienes o contratan servicios con fines de lucro. En este sentido, las directivas y reglamentos que brindan un concepto de consumidor, coinciden con los siguientes elementos: que sea una persona física y que adquiera bienes o contrate servicios sin fines de lucro.

PALABRAS CLAVES: Consumidor, Directiva, Vendedor, Contrato.

ABSTRACT: This paper aims to demonstrate how the concept of "consumer" has been a problem in Europe and the Spanish law; proof different judgement of Court of Justice of the European Communities, where it has been excluded to the legal entity that buy goods or hire services for profit. In this sense, the Directives and regulation that gives a concept of consumer, agree with the follow elements: that is a natural person and buy goods or hire services without non profit.

Doctor en Derecho por la Universidad de Salamanca, España. Profesor auxiliar de la Facultad de Derecho de la Universidad Juárez Autónoma de Tabasco, correo electrónico: $<$ henrrypleyares@hotmail.com>

Artículo recibido el 5 de junio de $2015 y$ aceptado para publicación el 26 de octubre de 2015. 
KEYWORDS: Consumer, Directive, Seller, Contract

\section{I.- CUESTIONES PREVIAS}

En 1973, la Asamblea Consultiva del Consejo de Europa aprobó la Carta Europea de protección de los consumidores, siendo el primer documento que reconoció los derechos de los consumidores al establecer las siguientes prerrogativas: "a) el derecho a la protección y a la asistencia de los consumidores; b) el derecho a la reparación del daño que resienta el consumidor por la circulación de productos defectuosos o por la difusión de mensajes engañosos o erróneos; c) el derecho a la información y a la educación; y d) el derecho de los consumidores a organizarse en asociaciones y a ser representados en diversos organismos, para expresar opiniones sobre decisiones políticas y económicas inherentes a la disciplina del consumo" ${ }^{\prime 1}$.

Asimismo, es importante aclarar que en 1975 se aprueba el Programa Preliminar de la Comunidad Económica de Protección al Consumidor². Dicho programa vio al consumidor como una persona interesada en los diferentes campos de la vida social, es decir, ya no como a un simple comprador, razón por la cual se le atribuyeron cinco derechos básicos: a) derecho a la protección de su salud y su seguridad; b) derecho a la protección de sus

1 Ovalle Favela (2006) p. 78; asimismo el autor pone de relieve tres momentos claves en materia de protección al consumidor, teniendo sus orígenes en los Estados Unidos de América. El primero tuvo lugar durante la mitad del siglo XX, señalando como los factores responsables el aumento de los precios de los artículos de consumo y los escándalos relativos a las sustancias farmacéuticas, lo cual dio como resultado la aprobación de la Ley sobre las sustancias alimenticias y farmacias, Ley sobre inspección de carne y la creación de la Comisión Federal para el Comercio. El segundo momento se da durante la mitad del decenio de los años treinta, con la propuesta de los consumidores por el aumento incontrolable de los precios en plena crisis económica, originando las reformas para fortalecer la Pure Food and Drug Act y con la ampliación de poderes normativos de la Comisión para el Comercio, a fin de combatir las actividades ilícitas o fraudulentas. Y el tercer y último período se inició a la mitad del decenio de los sesenta. Lo relevante de este periodo es el discurso del 15 de marzo de 1962 del presidente John F. Kennedy, en el cual señaló la necesidad de una legislación susceptible de asegurar los siguientes derechos a los consumidores: el derecho a la seguridad, el derecho a ser escuchado, el derecho a ser informado y el derecho a elegir libremente (Ibídem, págs. 77-78).

$2 \quad V i d$. Texto completo del Programa Preliminar, en Diario oficial de las Comunidades Europeas (en adelante DOCE), núm. C 092, de 25-IV-1975. 
intereses económicos ${ }^{3}$; c) derecho a la reparación de los daños; d) derecho a la información y la educación; e) derecho a la representación (derecho a ser escuchado).

En conexión con los cinco principios que se le reconocen al consumidor en este documento es importante destacar la opinión de Ovalle FAvela ${ }^{4}$ cuando aclara que "una comparación entre los cinco derechos fundamentales del consumidor reconocidos en forma explícita en el Programa Preliminar de la Comunidad Económica Europea, del 14 de abril de 1975, y los seis derechos que en forma implícita enuncian las Directivas de las naciones unidas, del 16 de abril de 1985, Ileva a la conclusión evidente de que ambos documentos reconocen exactamente los mismos derechos, con la única variante de que las directrices señalan por separado el derecho a la información y el derecho a la educación, aunque los regulan conjuntamente. La clara influencia del programa preliminar sobre las directrices se advierte con mayor intensidad en la reglamentación de cada uno de estos derechos".

Como podemos observar, el Programa Preliminar de 1975 se puede considerar como un hito en relación con los derechos de los consumidores, debido a su influencia en los posteriores tratado y acuerdos que reconocerían una mayor protección al consumidor en el ámbito comunitario.

Por otro lado, con la revisión del Tratado de Roma y la implementación del mercado interior, surge el Acta Única Europea ${ }^{5}$, la cual fue firmada en Luxemburgo el 17 de febrero de 1986 por nueve Estados miembros, a los que siguieron Dinamarca e Italia, entrando en vigor el 1 de julio de 1987. Lo relevante de dicha acta en la protección del consumidor es la previsión del artículo $100 \mathrm{~A}$, el cual define la integración de un mercado sin fronteras interiores, en el que la libre circulación de mercancías, personas, servicios y capitales estará garantizada. A nuestro parecer, esta acta no produjo grandes cambios en lo que respecta al ámbito del consumo.

3 Bajo esta denominación ("intereses económicos"), señala Botana García: "quedan englobadas una serie de reglas dirigidas a proteger al consumidor frente a contratos que incluyen cláusulas abusivas, a la publicidad engañosa, a los métodos de comercio agresivos, a la insuficiencia de los servicios de asistencia a la clientela etc. En definitiva, con el derecho a la protección de los intereses económicos del consumidor se está haciendo referencia al tratamiento y control de aquellas actividades comerciales que puedan serle económicamente perjudiciales de forma injustificada" (BOtANA García (1994) pp. 20-21).

4 Ovalle Favella, op.cit., pág. 81.

5 Vid. Texto completo del Acta Única Europea (DOCE núm. L 169, de 29-VI-1987). 
Siguiendo con la mejora de protección al consumidor en el ámbito Europeo el 7 de febrero de 1992 se firma el Tratado de la Unión Europea (Tratado de Maastricht) ${ }^{6}$, el cual reguló una serie de acciones concretas en materia de consumo (art. 129), quedando redactado de la siguiente forma: "1. La comunidad contribuirá a que se alcance un alto nivel de protección de los consumidores mediante: a) Medidas que adopte en virtud del artículo $100 \mathrm{~A}$ en el marco de la realización del mercado interior. b) Acciones concretas que apoyen y complementen la política llevada a cabo por los Estados miembros a fin de proteger la salud, la seguridad y los intereses económicos de los consumidores, y de garantizarles una información adecuada. 2. El consejo con arreglo al procedimiento previsto en el artículo 189 B y previa consulta al comité Económico y social, adoptará las acciones concretas mencionadas en la letra b) del apartado 1. 3. Las acciones que se adopten en virtud del apartado 2 no obstarán para que cada uno de los Estados miembros mantenga y adopte medidas de mayor protección. Dichas medidas deberán ser compatibles con el presente Tratado. Se notificará a la comisión".

La previsión del artículo comentado fortalece el mercado común y, por lo tanto, se incentiva la compra de bienes y contratación de servicios dentro de los distintos Estados miembros, garantizándose a su vez una elevada protección jurídica a los consumidores. Asimismo es importante mencionar que el Tratado que venimos comentando, introdujo la noción de "consumidor normalmente informado" ${ }^{\prime 7}$ y la denominada labelling doctrine, figuras cuyo

6 Vid. Texto completo del Tratado de la Unión Europea (DOCE núm. C 224, de 31 VIII- 1992).

7 Cfr. González Vaqué (1999) pp. 5-8, el autor señala que con el nuevo artículo 129 A del Tratado de Maastricht no sólo se alcanza un elevado nivel de protección al consumidor, sino que también se establecen medidas concretas como la protección de la salud, la seguridad y los intereses económicos de los consumidores, y de garantizarles una información adecuada (la cursiva es nuestra). En su estudio, González VAQUÉ hace un análisis de las sentencias más relevantes que se han establecido en el ámbito de la Unión Europea, en relación con la noción de "consumidor informado", prestando especial atención a la sentencia Gut Springenheide de 16 de julio de 1998. En dicha sentencia la cuestión debatida fue la demanda en contra de la empresa oberkreisdirektor des Kreises SteinfurtAmt für Lebensmittelüberwachung, comercializadora de huevos, ya que en el embalaje de los huevos comercializados se incluía una nota con la mención siguiente: "10 huevos frescos-6 cereales" el Tribunal consideró que dicha nota inducia a error al consumidor, ya que la gallinas no se alimentan sólo de 6 cereales y que los huevos ofrecen cualidades especiales, y que el artículo 14 del reglamento 1907/90 señala: los embalajes no podrán llevar más indicaciones que las previstas en el presente reglamento (vid. Texto completo de Reglamento (CEE) n 1907/90, del Consejo de 26 de junio de 1990 relativo a deter- 
objetivo principal es el de evitar, entre otras cosas, la publicidad engañosa. A todo esto habría que añadir que la consolidación de las expresiones mencionadas se ve reflejada en normas como la Directiva 2006/114/CE ${ }^{8}$ del Parlamento Europeo y del Consejo de 12 de diciembre de 2006 sobre publicidad engañosa y publicidad comparativa, que sustituye a la anterior Directiva 84/450/CEE del Consejo, de 10 de septiembre de 1984, sobre publicidad engañosa y comparativa (arts. 2,3 y 4), así como la Directiva 2005/29/CE, de prácticas comerciales desleales (arts. 6 y 7). Por lo tanto, cuando las empresas realicen negocios con consumidores tienen la obligación de informarle de todos sus derechos, ya que de incumplir dicha obligación se harían acreedoras a la sanción correspondiente, dependiendo del caso en concreto.

Tuvieron que pasar cinco años de la celebración del Tratado de la Unión Europea para que surgiera el Tratado de Ámsterdam ${ }^{9}$, el cual modificó varios aspectos sustanciales en materia de protección al consumidor, por ejemplo: la inclusión de nuevos derechos de los consumidores, la distinta ubicación de los mismos, la incorporación de la denominada "cláusula horizontal" en la política de protección de consumidores, la clarificación desde una perspectiva jurídico formal del tipo de actuaciones específicas que se podrán adoptar en el ámbito comunitario para la protección de los consumidores y, por último, la supervisión de medidas que apoyen y complementen la política llevada a cabo por los Estados miembros ${ }^{10}$. A este Tratado le siguieron

minadas normas de comercialización de huevos (DOCE núm. L 173, de 6-VII- 1990). El Tribunal dictó sentencia, notificando a la empresa que suprimiera dicha leyenda, además de imponerle una multa; este precedente se estableció en razón de la noción de un consumidor medio, normalmente informado y razonable, atento, perspicaz, sin haber realizado evaluación alguna, ni informes de opinión o informes periciales.

$8 \quad$ Vid. DOCE núm. L 376 de 27-XII-2006.

9 Vid. El Tratado de la Unión Europea (TUE), firmado en la ciudad neerlandesa de Maastricht el 7 de febrero de 1992, entró en vigor el 1 de noviembre de 1993. DOCE núm. C 325, de 12-XII-2002, versión consolidada.

10 Vid. Corchero Pérez y Grande Murillo (2007) pp. 58-60:

Tales medidas son las siguientes:

a) Plan de Acción de Prioridades de la Política de los Consumidores (que comprendió los años de 1996-1998), en cuyo marco se promulga la Directiva 98/127/CE del Parlamento Europeo y del Consejo de 19 de mayo de 1998 relativa a las acciones de cesación de los intereses de los consumidores; y el Plan de Acción sobre Acceso de los Consumidores a la Justicia y Reglamentación de los Litigios de Consumo en el Mercado Interior.

b) El Plan de Acción Sobre Política de los Consumidores (de 1999 a 2001): durante este periodo surgen las Euroventanillas con el fin de que los consumidores tengan un mejor contacto con las empresas. Se dictan las recomendaciones, CE/98/228 relativa al diálogo 
otras medidas adoptadas por la Unión Europa (en adelante UE), para seguir fortaleciendo la política de protección al consumidor.

Una vez visto cómo se ha desarrollado de manera general la protección del consumidor en Europa, pasaremos a ver cómo se ha materializado dicha protección.

\section{II.- PRÁCTICAS Y CONTRATOS REGULADOS PARA PROTEGER AL CON- SUMIDOR}

La UE ha dictado una serie de normas, en forma de Directivas y Reglamentos, con el fin de dar seguridad jurídica al consumidor. En estas normas se regulan en su mayoría los derechos de los consumidores en determinados sectores. Por razones de espacio, sólo nos enfocaremos a aquellas que consideramos más importantes, mencionando las demás de manera escueta a pie de página ${ }^{11}$.

al seguimiento y a la información para facilitar la transición al Euro como única moneda y CE/98/287 en relación con la doble indicación de precios y otros importes monetarios. Por lo que a nuestro tema toca, es importante señalar que durante dicho plan surge la Directiva 2000/31/CE del parlamento Europeo y del Consejo, relativo a determinados aspectos jurídicos de los servicios de la sociedad de la información y del comercio electrónico.

c) El 26 de febrero del año 2001 se firma el Tratado de Niza entrando en vigor el 1 de febrero de 2001, el cual no produjo ninguna modificación en lo referente a los consumidores, quedando intacto el artículo 153 del Tratado de Ámsterdam.

d) De 2001 a 2005, la Unión Europea se preocupó por desarrollar estrategias en materia de política de consumidores, surgiendo la Directiva de servicios financieros (Directiva 2002/65/CE).

11 Así en el ámbito del Derecho secundario de la Unión Europea encontramos Directivas que protegen al consumidor en diversos sectores, a modo de ejemplo señalamos las siguientes: - Directiva 2000/43/CE, sobre el principio de igualdad de trato de las personas independientemente de su origen racial o étnico, - Directiva 2004/122/CE sobre el principio de igualdad de trato entre hombres y mujeres al acceso a bienes y servicios y su ministro; y - Directiva 2007/64/CE, sobre servicios de pago, - Directiva 94/19/CE, sobre los sistemas de garantía de depósitos; - Directiva 92/49/CEE, sobre seguros distintos del seguro de vida; - Directiva 2002/83/CE, sobre seguro de vida; - Directiva 2002/92/ CE, sobre la medición en los seguros; - Directiva 2003/71/CE, sobre folletos; - Directiva 2003/6/CE, sobre operaciones con información privilegiada y la manipulación del mercado (abuso del mercado); - Directiva 85/611/CEE, sobre determinados organismos de inversión colectiva (OICVM); - Directiva 2004/39/CE, sobre mercados de instrumentos financieros; - Directiva 97/9/CE, sobre los sistemas de indemnización de los inversores, 
- Directiva 2000/35/CE, sobre morosidad en las operaciones comerciales; y - Directiva 2006/114/CE, sobre publicidad engañosa y publicidad comparativa. El Reglamento tiene un alcance general. Es obligatorio en todos sus elementos y directamente aplicable en cada Estado miembro (art. 288(2) del Tratado de Funcionamiento de la Unión Europea (en adelante TFUE). En cambio la Directiva obliga al Estado miembro, en cuanto al resultado que deba conseguirse, dejando, a las autoridades nacionales la elección de la forma y de los medios (art. 288(3) TFUE. (Cfr. GARCÍA-CRUCES GONZÁLEZ (1989) pp. 370-373). Vid., artículo 288(3) TFUE. Vid. Mangas Martín Y LiÑán Nogueras (2010) pp. 368-369. Para estos autores el efecto directo de las Directivas "es invocable no sólo en las relaciones del particular con las administraciones públicas -denominadas relaciones verticales, como los casos Van Gend en Loos, Salgoil o Lütticke-, sino también en las relaciones entre particulares (relaciones horizontales) en las que el sujeto de la obligación reclamada es un particular". No obstante hay que aclarar también que el efecto horizontal de las Directivas entre particulares sólo se aplicará cuando el Estado actúa como particular (sentencia Van Dyn), y no cuando las relaciones entre particulares (sentencia Marshall). Una Directiva a diferencia del Reglamento no tiene alcance general, es decir, no puede por sí sola crear obligaciones a cargo de un particular, cuando no ha sido transpuesta por el Estado miembro, por lo tanto, sus disposiciones no pueden ser invocadas, en su calidad de tal contra dicha persona. No obstante, una disposición clara, precisa e incondicional de una Directiva que tiene por objeto conferir derechos o imponer obligaciones a los particulares no puede aplicarse como tal en el marco de un litigio exclusivamente entre particulares. Para el caso de que un Estado miembro no haya transpuesto una Directiva y se ocasionen daños y perjuicios a los particulares como resultado de la no transposición de la Directiva, el TJCE ha establecidos las siguientes soluciones alternativas:

a) Principio de "interpretación conforme". De acuerdo con este principio los órganos jurisdiccionales de los Estados miembros tienen la obligación de interpretar el Derecho interno, con el fin de garantizar la aplicación de éste, conforme a la Directiva; en otras palabras, se busca alcanzar la efectividad del resultado perseguido por la Directiva. Sin embargo, la interpretación que realicen los tribunales no pueden ir en contra de las disposiciones del Estado miembro.

b) "Responsabilidad del Estado miembro". En caso de que una Directiva no haya sido transpuesta en tiempo, o incluso si hubiera sido transpuesta, pero su transposición ocasionara daños y perjuicios a los particulares por no alcanzarse el objetivo o fin establecido, el Estado miembro está obligado a reparar los daños a particulares como consecuencia de su incumplimiento.

c) "Principios generales". EI TJCE ha admitido la aplicación de un principio general cuando una Directiva no sea admitida en un litigio por no haberse transpuesto (Vid. Sentencia Mangold (C-144/04) DO C 36 de 11/06/2006, pág. 10).

d) "Distinción entre el efecto directo de sustitución e invocabilidad de exclusión". Con esta regla el TJCE ha dejado claro la no sustitución del Derecho nacional por una Directiva con el fin de obligar a los particulares a cumplir con sus obligaciones. En cambio, el 
Con el objeto de regular el mercado interior en materia de protección del consumidor, se dicta la Directiva 93/13/CEE, sobre cláusulas abusivas ${ }^{12}$. Esta norma tal y como se explica en su Exposición de Motivos, tiene como fin evitar "cláusulas abusivas en los contratos celebrados con consumidores por un profesional, y que, si a pesar de ello figuraran tales cláusulas, éstas no obligarían al consumidor y el contrato seguirá siendo obligatorio para las partes en los mismos términos, siempre que las cláusulas abusivas no afecten su existencia". En el artículo 3 de la citada norma se brinda la definición de cláusula abusiva $^{13}$, y a modo ejemplificativo se incluye una lista en su anexo.

La transposición de esta Directiva al ordenamiento jurídico español se realizó a través de la Ley 7/1998, sobre condiciones generales de la contratación (LCGC), en cuyo artículo 8.1 y 2 se hace la distinción entre "control de legalidad", aplicable a relaciones entre empresarios y con consumidores, y "control de contenido" en sede de contratos de consumo, con el fin de evitar cláusulas abusivas como las que establezcan la renuncia a derechos reconocidos por el adherente y las que atenten contra el principio de la buena fe y el justo equilibrio entre las partes ${ }^{14}$.

principio de invocabilidad de exclusión tiene con finalidad excluir el Derecho nacional, cuando éste sea contrario a la Directiva, sin embargo, el TJCE nunca ha hecho uso de este recurso,

12 DO L 121 de 15.5.1993, pág. 1.

13 Artículo 3 Directiva 93/13/CEE: "1. Las cláusulas contractuales que no se hayan negociado individualmente se considerarán abusivas si, pese a las exigencias de la buena fe, causan en detrimento del consumidor un desequilibrio importante entre los derechos y obligaciones de las partes que se derivan del contrato.

2. Se considerará que una cláusula no se ha negociado individualmente cuando haya sido redactada previamente y el consumidor no haya podido influir sobre su contenido, en particular en el caso de los contratos de adhesión. El hecho de que ciertos elementos de una cláusula o que una cláusula aislada se hayan negociado individualmente cuando haya sido redactada no excluirá la aplicación del presente artículo al resto del contrato si la apreciación global lleva a la conclusión de que se trata, no obstante, de un contrato de adhesión. El profesional que afirme que una cláusula tipo se ha negociado individualmente asumirá plenamente la carga de la prueba".

3. El Anexo de la presente Directiva contiene una lista indicativa y no exhaustiva de cláusulas que pueden ser declaradas abusivas".

14 Cfr. Vicent Chuliá (2004) p. 55. Las condiciones generales se caracterizan por los siguientes aspectos: se incorporan al cuerpo del contrato, son cláusulas predispuestas (las empresas previamente las redactan), materializándose a través de formularios y se imponen, es decir, al consumidor no le queda otra más que aceptar o rechazar el contrato. 
Por otro lado, el control de inclusión tiene como objetivo brindar transparencia, claridad, concreción y sencillez, esto de acuerdo con el artículo 80.1 a y b del Texto Refundido de la Ley de Consumidores y Usuarios del año 2007 (en adelante TRLGDCU), teniendo el adherente conocimiento de las condiciones generales. En cambio con el control de contenido se trata de evitar que el empresario imponga cláusulas abusivas al consumidor ${ }^{15}$. En este sentido EguzQuiza BalmasedA, señala que las dos grandes cuestiones que se plantean en la contratación mediante condiciones generales son "a) el conocimiento de las condiciones que van a regir la relación contractual, cuestión de relieve para una formación de voluntad libre y consciente de lo contratado, y la aceptación de las mismas (control de incorporación o inclusión); y b) la valoración del carácter justo o abusivo de tales cláusulas (el control de contenido) $)^{\prime 16}$. Este último control cobra importancia en el marco de los contratos con consumidores, puesto que define a las cláusulas abusivas (art. 82 TRLGDCU) como "todas aquellas estipulaciones no negociadas individualmente y todas las prácticas no consentidas expresamente que, en contra de las exigencias de la buena fe causen, en perjuicio del consumidor y usuario, un desequilibrio importante de los derechos y obligaciones de las partes que se deriven del contrato"17.

La Directiva de cláusulas abusivas se encuentra actualmente en proceso de revisión. En la Propuesta de Directiva de Consumidores del año 2008 se preveía su refundición ${ }^{18}$; sin embargo, durante la revisión del Acquis Group

15 Cabe apuntar que el control de contenido se establece sólo en relaciones entre empresario y consumidor, y no entre empresarios. Su justificación se encuentra en la ausencia de negociación, con el fin de evitar entre otras cosas cláusulas abusivas. Esta función delimitadora alude al criterio de buena fe regulado en el artículo 1258 del Código Civil, no sólo como principio, sino también con el fin de que exista un equilibrio contractual, en la relación empresario consumidor. Vid, en este sentido Cámara Lapuente (2006), pp. 92-93, [...]: "y si se tiene en cuenta que el control de contenido de la Directiva sobre cláusulas abusivas encuentra su justificación en la ausencia de negociación, entonces la exclusión preconizada por el art. 4.2 puede estar justificada dentro del sistema diseñado y del modelo constitucional tanto comunitario como español. Los fallos del mercado que no permitan al consumidor contrastar ("negociar") la relación calidad/precio, serán corregidos por el Derecho de la competencia [...]").

16 Egusquiza Balmaseda (2002) pp. 24-26.

17 Vid, en este sentido, Gómez-Salvado Sánchez (2008) p. 142-145.

18 Vid. EIDENMüller et al (2012) pp. 127-128, para este autor una armonización en materia de cláusulas abusivas a nivel comunitario "tiene que ver con el ámbito razonable de la armonización de máximos. Por ejemplo, la armonización de máximos puede limitarse a reglas que se apliquen a cláusulas no negociadas individualmente en contratos entre empresa- 
se mencionaron los problemas en relación con el principio de armonización plena, razón por la cual la Directiva de los Consumidores del año 2011 (en adelante DDC), la excluyó.

Por otro lado como resultado de un exhaustivo proceso de consultas surge la Directiva 2005/29/CE, sobre prácticas comerciales desleales ${ }^{19}$, con el objetivo de fomentar la competencia y la confianza de los consumidores en las transacciones transfronterizas. La Directiva se estructura de la siguiente manera: una cláusula general, definición de prácticas engañosas y prácticas agresivas (arts. 6 y 7), acciones y omisiones; y una lista negra de "prácticas comerciales desleales" en su anexo número uno. En relación con el tema que nos ocupa, se considera "práctica engañosa", entre otras, la omisión del derecho de desistimiento por parte del empresario, pues se considera que tal información es sustancial al momento de celebrarse el contrato (art. 7.4 d).

Con la adopción de este tipo de medidas se reemplazan múltiples leyes y decisiones judiciales de carácter nacional. Asímismo, la Directiva comentada aporta una armonización plena y prevé el principio de reconocimiento mutuo entre los Estados miembros con el fin de eliminar las barreras del mercado interior. Cabe señalar que hasta antes de la aprobación de esta norma, la noción de "práctica comercial desleal" estaba sujeta a distintas interpretaciones por parte de los Estados miembros. Sin embargo, tal problemática ha quedado resuelta, al definirse lo que es una práctica comercial desleal: "todo acto, omisión conducta o manifestación, o comunicación comercial incluidas la publicidad y la comercialización, procedente de un comerciante y directamente relacionado con la promoción, la venta o el suministro de un producto a los consumidores" (art. 2, d) de la Dir. 2005/29, CE).

La Directiva de prácticas comerciales desleales se integró al ordenamiento jurídico español mediante la Ley 29/2009, del 30 de diciembre, por la que se modifica el régimen legal de la competencia desleal y de la publicidad para la mejora de la protección de los consumidores y usuarios ${ }^{20}$.

rios y consumidores; además, el criterio de abusividad puede no aplicarse a cláusulas que reflejen reglas nacionales de naturaleza imperativa o dispositiva. En estas circunstancias los Estados Miembros tendrían libertad para fijar criterios más exigentes por medio del Derecho imperativo (de consumo) y los efectos de la armonización de máximos se verían severamente socavados, no se conseguiría ninguna armonización sustantiva: ni los empresarios podrían usar un único pliego de condiciones generales, ni los consumidores podrían confiar en criterios similares en toda Europa $[\ldots]^{\prime \prime}$. DOCE L 149 de 11-6-2005.

20 Vid. Boletín Oficial del Estado (en adelante BOE) núm. 315, de 31-XII-2009. 
Aparte de las ya citadas, que se aplican de forma transversal, sea cual fuere el sector, existen otras Directivas que regulan una protección específica del consumidor en un determinado ámbito entre las que encontramos:

- Directiva sobre los derechos de los consumidores, aprobada en octubre de 2011;

- Directiva 2002/65/CE, sobre contratos a distancia de servicios financieros;

- $\quad$ Directiva 2000/31/CE, sobre comercio electrónico;

- Directiva 99/44/CE, sobre garantía en las ventas de consumo;

- $\quad$ Directiva 2008/122/CE, de aprovechamiento por turno;

- $\quad$ Directiva 90/314/CEE, sobre viajes combinados.

Es importante mencionar que estas Directivas, además de proteger al consumidor en determinados tipos contractuales y formas de conclusión del contrato, tienen como fin evitar que la fragmentación de las legislaciones nacionales represente un freno a los intercambios fronterizos y, por consiguiente, un obstáculo a la realización del mercado interior ${ }^{21}$.

\section{III.- REGULACIÓN DE UN SUJETO ESPECIAL: CONCEPTO DE CONSUMI- DOR}

Dentro del presente apartado, analizaremos cómo la figura del consumidor ha estado y sigue estando presente en las normas que se han dictado dentro del seno del marco comunitario europeo. Además de forma paralela a la normativa, el concepto de consumidor se ha ido consolidando por más de dos décadas a través de las sentencias del Tribunal de Justicia de las Comunidades Europeas (en adelante STJCE).

Si bien en un principio el concepto de "consumidor" fue tomado de la economía, hoy también forma parte de la ciencia jurídica tal y como ha apuntado la doctrina ${ }^{22}$. Por otra parte, se han desarrollado distintas nociones

21 Resulta ser el dogma de los considerandos de todas las Directivas anteriormente mencionadas.

22 Vid. Lasarte Álvarez (2007) p. 55; Lete Achirica (1998) p. 184: "[e]l término "consumidor", que viene empleándose con habitualidad en la terminología de los sistemas jurídicos occidentales desde hace aproximadamente dos décadas, no es, sin embargo, un concepto originariamente jurídico sino socio económico. El Derecho lo ha tomado prestado para 
de consumidor, unas de carácter pragmático y otras de desarrollo ${ }^{23}$. Así, encontramos los siguientes conceptos del consumidor:

1.- Noción abstracta: se identifica consumidor con "ciudadano", a quien se debe tutelar el derecho a la información y a la educación. Esta noción guarda estrecha relación con los programas y políticas de gobierno, los cuales tienen como uno de sus principales objetivos la protección del consumidor ${ }^{24}$. Ello se deja ver en el artículo 51 de la Constitución española al declarar: "los poderes públicos garantizarán la defensa de los consumidores y usuarios, protegiendo, mediante procedimientos eficaces, la seguridad, la salud y los legítimos intereses económicos de los mismos. Los poderes públicos promoverán la información y la educación de los consumidores y usuarios, fomentarán sus organizaciones y oirán a éstas en las cuestiones que puedan afectar a aquéllos, en los términos que la Ley establezca". De acuerdo con lo anterior, el Estado garantiza la protección de los consumidores y usuarios, respetando y salvaguardándola como uno de los principios constitucionales. Como consumidores se protege así a todos los ciudadanos, siendo esta idea tomada del conocido discurso del presidente Kennedy ${ }^{25}$. De esta manera, la noción abstracta de consumidor se identifica con la de ciudadano.

2.- Noción jurídica y material: el consumidor jurídico será, conforme a la normativa comunitaria y nacional, quien ejecute el acto de contratación del servicio o compra del producto ${ }^{26}$. En cambio, el consumidor material es aquella persona que hace uso o disfrute del bien o servicios, teniendo derecho a la sanidad y seguridad. Además, puede ejercer los derechos, garantías y acciones que le correspondan como resultado de la adquisición del bien o contratación de servicios $^{27}$. Por ejemplo, demandar la responsabilidad de daños por productos o servicios defectuosos ${ }^{28}$.

caracterizar las relaciones jurídicas merecedoras de cierta protección como consecuencia de la diversa posición que los empresarios y los particulares ocupan en el mercado".

23 Cfr. Reyes López (2009) p. 88

24 Vid. Bercovitz Rodríguez-Cano (1992) p. 25.

25 Tal discurso fue pronunciado el 15 de marzo de 1962 por el presidente de los Estados Unidos John F. Kennedy ante el congreso de su país. Vid. Gómez Calero (1994) p. 24.

26 Vid. Cámara Lapuente (2011) p. 112.

27 Cfr. Fernández Gimeno (2005) pp. 98-99, para este autor el concepto concreto de consumidor tiene utilidad cuando: "[a]tribuye derecho que pueden ejercitar individualmente en su interés particular. En este criterio se concibe al consumidor como partícipe en un determinado acto de consumo".

28 Vid. Directiva 85/374, sobre daños causados por productos defectuosos. Esta norma tiene como objetivo proteger a la persona perjudicada que adquiere bienes para un uso perso- 
3.- Noción de "consumidor-cliente": este concepto tiene un alcance amplio, incluyéndose cualquier persona que en el mercado adquiera un bien o disfrute de un servicio por cualquier título.

\section{4.- Comprador, arrendatario, usuario, derechohabiente, espectador, etc.} El consumidor como "cliente potencial": este concepto "incorpora los aspectos sociológicos para determinar quiénes deben ser considerados como consumidores en cada caso es aplicable en relación con las normas del Derecho de la competencia en sentido amplio, esto es, Derecho antitrust y regulación contra la competencia desleal, así como en materias de marcas" ${ }^{\prime 29}$. Esta noción halla su fundamento en el artículo 83.1 del Tratado Constitutivo de la Unión Europea (hoy artículo 101 del TFUE), el cual prohíbe los acuerdos, decisiones y prácticas concertadas colusorias entre las empresas para perjudicar al consumidor. Con este tipo de medidas se trata de proteger a los destinatarios potenciales, evitándose prácticas prohibidas en el mercado ${ }^{30}$.

Como podemos observar, no hay una noción uniforme del consumidor. En consecuencia, su delimitación vendrá determinada en atención al sector de que se trate ${ }^{31}$, tal y como veremos en el siguiente apartado.

nal, y además que el acto de consumo se considere para un uso privado. Esta Directiva ha sido adaptada al ordenamiento jurídico español a través del TRLGDCU (arts. 135-149).

29 Cfr. Bercovitz Rodríguez-Cano (2005) p. 21-22.

30 Ibídem.

31 Vid. Bercovitz Rodríguez-Cano (1987) p. 108, este autor hace referencia a la legislación alemana y se distinguen tres conceptos según el ámbito jurídico al cual se esté: [...] "se hace notar que en el Derecho alimentario la noción de consumidor se relaciona con el consumo doméstico privado; en el Derecho de la competencia se hace referencia, en general, al consumidor final, y en el Derecho europeo de cárteles y en materia de responsabilidad del fabricante, el consumidor es, en general, el cliente, sin que se exija que se trate de un consumidor final o doméstico. Esa diferenciación es debida a la finalidad propia de cada ley". Además como señalan Díaz Alabart y Álvarez Moreno: “El mercado único debe velar por un elevado nivel de protección de todos los consumidores, pero debiendo prestar especial atención a un tipo de consumidor, el vulnerable, con el fin de tomar en consideración sus necesidades específicas y reforzar sus capacidades, más por otra parte no hay que olvidar que casi todos los consumidores en algún momento de su vida pueden llegar a ser vulnerables, debido simplemente a factores externos y a sus interacciones con el mercado o porque experimenten dificultades para acceder a la información adecuada dirigida a los consumidores y entenderla, y por tanto precisen de una protección especial. La vulnerabilidad puede nacer por la falta de comprensión de la información que reciben o del desconocimiento de los sistemas de reclamación, lo que sucede en muchos casos en las ventas que se realizan a domicilio o a través del teléfono. Por lo que los problemas de la vulnerabilidad pueden tener causas muy distintas, pueden 


\section{LA PROBLEMÁTICA DE SU DELIMITACIÓN CONCEPTUAL}

La mayoría de las Directivas, normas reglamentarias e iniciativas en materia de protección al consumidor coinciden con el siguiente concepto de consumidor: "toda persona física que actúe con un propósito ajeno a su actividad comercial, empresa, oficio o profesión". Sin embargo, reiteramos, el concepto no es único, y no es claro el elemento de la "no profesionalidad". Además, el Tribunal de Justicia de las Comunidades Europeas (en adelante TJCE) en sus diversas sentencias nunca ha delimitado tal concepto, sino sólo ha excluido de manera general a las personas jurídicas que actúen con fines de lucro ${ }^{32}$, tal y como veremos dentro de este mismo apartado.

A nivel comunitario, las siguientes normas coinciden con el concepto de consumidor, el cual como veremos también es recogido por el ordenamiento jurídico español:

- Directiva 2002/65/CE, sobre contratos de servicios financieros ${ }^{33}$;

- $\quad$ Directiva 2000/31/CE, sobre comercio electrónico ${ }^{34}$;

- Directiva 2005/29/CE, sobre prácticas comerciales desleales ${ }^{35}$;

- $\quad$ Directiva 93/13/CEE, sobre cláusulas abusivas ${ }^{36}$;

- $\quad$ Directiva 2008/48/CE, sobre al crédito al consumo ${ }^{37}$.

surgir en situaciones muy diversas y pueden requerir medidas de distinto tipo en cada lugar"; Díaz Alabart y Álvarez Moreno (2014), pp. 34 y 35.

32 Vid., más sobre este punto, en Cámara Lapuente (2011 b), op.cit., pp. 129 y ss.

33 Artículo 2 (d) de la Directiva 2002/65/CE, relativa a la comercialización a distancia de servicios financieros destinados a los consumidores: "toda persona física que, en los contratos a distancia, actúe con un propósito ajeno a su actividad comercial o profesional". Artículo 2 (e) de la Directiva 2000/31/CE, sobre comercio electrónico: "cualquier persona física que actúe con un propósito ajeno a su actividad económica, negocio o profesión".

35 Artículo 2 (a) de la Directiva 2005/29/CE, sobre prácticas comerciales desleales: "cualquier persona física que, en las prácticas comerciales contempladas por la presente Directiva, actúe con un propósito ajeno a su actividad comercial o profesional".

36 Artículo 2 (b) de la Directiva 93/13/CEE, sobre las cláusulas abusivas: "toda persona física que, en los contratos regulados por la presente Directiva, actúe con un propósito ajeno a su actividad profesional".

37 Artículo 3 (a) de la Directiva 2008/48/CE, de crédito al consumo, señala: consumidor es la "persona física que, en las operaciones reguladas por la presente Directiva, actúa con 
- $\quad$ Directiva de consumidores del año $2011^{38}$.

- Directiva 99/44/CE, sobre garantía en las ventas de consumo ${ }^{39}$;

- $\quad$ Directiva 90/314/CEE, sobre viajes combinados ${ }^{40}$;

- $\quad$ Directiva 2008/122/CE, sobre tiempo compartido ${ }^{41}$.

Estás Directivas toman ciertos criterios, los cuales han servido como punto de partida a la hora de considerar a una persona como "consumidor". Dentro de estos criterios encontramos el "acto de consumo", "el destino de

fines que están al margen de su actividad comercial o profesional...".

38 Artículo 2.1 de la Directiva sobre Derecho de los consumidores del año 2011: "toda persona física que, en contratos regulados por la presente Directiva, actúe con un propósito ajeno a su actividad comercial, empresa, oficio, o profesión".

39 Artículo 1.2.a) de la Directiva 1999/44/CE, referente a determinados aspectos de la venta y las garantías de los bienes de consumo: "toda persona física que, en los contratos a que se refiere la presente Directiva, actúa con fines que no entran en el mercado de su actividad profesional". Vid., en este sentido GonZález Vaqué (2005), en: http://www.consumoinc.es/. [Con acceso el 12-XII-de-2010], especialmente notal pie número 31, en donde, el autor declara el ámbito de aplicación de esta Directiva no sólo a las personas físicas, sino también se incluyen a las personas jurídicas.

40 Artículo 2.4 de la Directiva 90/314/CEE, relativa a los viajes combinados: "la persona que compra o se compromete a comprar el viaje combinado ("el contratante principal"), la persona en nombre de la cual el contratante principal se compromete a comprar el viaje combinado ("Ios demás beneficiarios") o la persona a la cual el contratante principal u otro beneficiario cede el viaje combinado". En términos parecidos se expresa el numeral 151. g) del TRLGDCU: "cualquier persona en la que concurra la condición de contratante principal, beneficiario o cesionario". Como puede observarse a diferencia de otros contratos en los que sólo se protege al consumidor cuando actúe sin fines de lucro, la regulación de los viajes combinados amplía su ámbito de aplicación a cualquier persona, por lo cual las personas jurídicas también gozarán de los derechos otorgados por la Directiva 90/314/CEE, sobre viajes combinados. De esta manera el TRLGDCU amplía su protección tanto al cliente contratante del viaje como al cesionario, o beneficiario (art. 152). Vid, en este sentido: Esteban De La Rosa (2003) pp. 68-69; Martínez Espín (2010), en: www.uclm.es/cesco/pdf/comentarios/2.pdf. [Con acceso el 3-III-2010]. Ambos autores entiende entendible el ámbito de aplicación de la Directiva de viajes combinados a las personas jurídicas.

41 Artículo 2 (f) de la Directiva 2008/122/CE, de Timeshare, define al consumidor: "toda persona física que actúe con fines ajenos con su actividad económica, negocios, oficio o profesión". 
los bienes o servicios" y la "posición de los sujetos contratantes", ya sea que se traten de personas físicas o personas jurídicas. A continuación analizaremos de manera general los criterios mencionados.

1.- "El acto de consumo" tal y como lo define Lasarte Álvarez es "el acto jurídico (un contrato casi siempre) que permite obtener un bien o un servicio con vistas a satisfacer una necesidad personal o familiar. A diferencia del comerciante, a quien se exige la habitualidad, un acto de consumo aislado sería suficiente para calificar de consumidor al que lo realiza". Para este autor, a diferencia del concepto de "contrato de consumo", el cual restringe su ámbito de aplicación a la calidad de consumidor, el acto de consumo es un concepto más amplio, el cual se caracteriza por ser un acto jurídico, consistente en aprovechar el bien o servicio objeto del contrato ${ }^{42}$.

2.- "El destino de los bienes o servicios" es tenido en cuenta para la calificación del adquiriente o usuario como consumidor, pues su contratación destinada a uso personal, sin fines de lucro, es elemento definidor de aquél. El elemento comentado cobra importancia, ya que "lucro" en términos económicos significa provecho o ganancia personal, tal y como lo hacen las empresas trasnacionales. En este sentido, el TJCE ha dejado claro que no se consideran consumidores las personas físicas o jurídicas que actúan dentro de un ámbito profesional. Asimismo el TJCE en la sentencia Gruber delimitó los parámetros que deben seguirse para que una persona se considere consumidor mixto ${ }^{43}$, tal y como veremos en el presente apartado.

3.- La protección jurídica se otorga tanto a las "personas físicas como jurídicas", siempre y cuando actúen en un ámbito ajeno a su actividad profesional o comercial (p. ej., las asociaciones comunitarias que actúan sin fines de lucro).

42 Vid. Lasarte Álvarez, op.cit., p. 60.

$43 \quad V i d .$, punto 17 de la DDC cuando señala: "La definición de consumidor debe incluir a las personas físicas que actúan fuera de su actividad comercial, empresa, oficio o profesión. No obstante, en el caso de los contratos con doble finalidad, si el contrato se celebra con un objeto en parte relacionado y en parte no relacionado con la actividad comercial de la persona y el objeto comercial es tan limitado que no predomina en el contexto general del contrato, dicha persona deberá ser considerada como consumidor". 
El TJCE en las sentencias Gruber ${ }^{44}$ y Engler ${ }^{45}$, al pronunciarse sobre el forum actoris ${ }^{46}$, ha delimitado, entre otras cosas, qué criterios deben seguirse a la hora de considerar un bien destinado a un uso parcialmente profesional y parcialmente ajeno a su actividad profesional, así como cuándo se entiende celebrado un contrato de consumo.

El señor Gruber, agricultor y dueño de una granja en Austria compró a la empresa Bay Wa, domiciliada en Alemania, una partida de tejas que necesitaba para restaurar la granja, la cual comprendía una pocilga para más de 200 cerdos, así como una gran nave para maquinaria y silos para piensos. En ellas se almacenaba entre el $10 \%$ y el $15 \%$ de la cantidad de forraje necesario para la explotación. La parte de la granja destinada al uso como vivienda familiar era ligeramente superior al $60 \%$ de la superficie total útil del inmueble.

El señor Gruber tuvo conocimiento de la empresa Bay Wa a través de unos folletos publicitarios, los cuales fueron distribuidos en Alemania y Austria, por lo cual realizó el pedido de las tejas por medio de comunicación telefónica. Sin embargo, el señor Gruber nunca menciona su calidad de agricultor a la empresa, razón por la cual, el Tribunal de Primera Instancia (Landesgericht steyr) se declaró competente para conocer del litigio, señalando que se reunían los requisitos del artículo 13 del Convenio de Bruselas I. No obstante, el Tribunal de apelación austríaco se declaró incompetente para conocer del asunto. Por tal motivo, el Tribunal de casación planteó la cuestión prejudicial al TJCE haciendo las siguientes interrogantes:

En caso de afectación parcial de la prestación a un uso privado iresulta determinante, para apreciar la condición de consumidor a efectos del artículo 13 del Convenio de Bruselas, que predominen los usos privados o los usos profesionales? ¿Qué criterios deben seguirse para comprobar si predominan unos u otros? ¿Depende de la determinación del uso, de las circunstancias objetivamente discernibles para la otra parte del contrato celebrado por el consumidor? En caso de duda, ¿debe prevalecer la calificación de contrato celebrado por un consumidor?

Sin embargo, el TJCE no le otorgó la razón al señor Gruber, basándose en las siguientes conclusiones:

\footnotetext{
44 STJCE de 20 de enero de 2005, asunto C-464/01, Johann Gruber C. Bay Wa.

45 STJCE de 20 de enero de 2005, asunto C-27/02, Petra Engler contra Janus Versand GmbH.

46 Vid., en este sentido, Añoveros Terradas (2005) pp. 1737-1744.
} 
1. "Una persona que celebre un contrato para un uso en parte relacionado con su actividad profesional y en parte ajeno a la misma no puede invocar la regla de competencia de los artículos 13 y siguientes del Convenio de Bruselas I, a menos que el uso relacionado con su actividad profesional sea insignificante.

2. Para determinar si una persona ha celebrado un contrato para un uso que puede considerarse ajeno a su actividad profesional en el sentido de los artículos 13 y siguientes del Convenio de Bruselas I y no es necesario tener en cuenta las circunstancias objetivamente discernibles. A no ser que el propio consumidor se haya presentado como si actuara en el marco de actividad profesional y la otra parte no tuviera conocimiento de ello.

3. Debe considerarse que cuando un consumidor recibe en el Estado que está domiciliado una oferta telefónica específica de un proveedor establecido en otro Estado contratante y, posteriormente, compra a dicho proveedor los bienes o servicios así ofrecidos, la celebración del contrato ha ido precedida de una oferta especialmente hecha en el sentido del artículo 13, número 3, letra a), del Convenio de Bruselas, aun cuando sus estipulaciones concretas estén basadas en una oferta posterior, no recibida en el Estado del domicilio del consumidor.

4. A efectos del artículo 13, letra b), del Convenio de Bruselas, un consumidor realiza los actos necesarios para la celebración de un contrato en el Estado en el que está domiciliado cuando comunica su aceptación de una oferta desde dicho Estado, con independencia del lugar en el que se haya hecho la oferta y del conducto utilizado" ${ }^{\prime 7}$.

En el caso que venimos comentando, el TJCE ha establecido las directrices de cuándo se está ante un contrato mixto de consumo, que implica la existencia de un "consumidor" al que aplicar su normativa protectora: siempre y cuando el uso profesional carezca de importancia, teniendo una relevancia mínima; lo cual, como vimos, no ocurrió en las cuestiones que se plantearon en el asunto Gruber. Por lo tanto, en dicho caso no existía un "consumidor" a quien tutelar, pues existía claramente un lucro o ganancia en términos económicos.

47 Vid. Texto completo de la sentencia en: http://curia.europa.eu. [Con acceso el 10-XIIde-2010]. 
En cambio, en la cuestión de fondo del asunto Engler se puso en tela de juicio la aplicación de la sección IV del Convenio de Bruselas I, cuestionándose si existía realmente un contrato "de consumo"48.

Los hechos fueron los siguientes: la señora Engler recibió un correo por parte de la empresa Janus Versand, domiciliada en Alemania, el cual contenía un bono de pago con un valor aproximado de 455.000 ATS (33.066,14 euros), y un catálogo de los productos en venta, lo cual hizo creer a la Sra. Engler que había ganado dicha cantidad y que para recibirla sólo debía rellenar el bono y reenviarlo a la empresa, lo cual realizó. Sin embargo, la Sra. Engler no hizo pedido alguno de los productos ofrecidos en el catálogo, por lo cual la empresa se negó a pagar el premio. Así las cosas, la Sra. Engler interpuso su demanda en contra de la empresa anunciadora en un tribunal austríaco, el cual dudó de la aplicación del Convenio de Bruselas I y planteó la cuestión perjudicial ante el TJCE, en el sentido de que si al caso en debate le era aplicable la normativa de contratos internacionales celebrados por consumidores. El TJCE respondió que al caso en cuestión no se podía aplicar el Reglamento Bruselas I (art. 5), debido a que no existía relación contractual alguna entre la señora Engler y la empresa anunciadora ${ }^{49}$ y, en consecuencia, la señora Engler no era "consumidor" a efecto de la normativa que pretendía aplicarse.

Por otra parte, los Estados miembros pueden incluir a las personas jurídicas dentro del concepto de consumidor, siempre y cuando éstas actúen sin fines de lucro. El TJCE trató el tema en el asunto Di Pinto ${ }^{50}$. El Sr. Di Pinto, gerente de la empresa Groupement de l'immobilier et du fonds de commerce, que difundía una revista en la que se insertaban ofertas de fondos de comercio, hizo visitar, en sus domicilios o en sus lugares de trabajo, a comerciantes que querían vender sus fondos de comercio, con la intención de que los ofertasen mediante anuncios en su revista ${ }^{51}$. Ante tal situación, el Tribunal de Grand Instance de París condenó al Sr. Di Pinto a la pena de un año de prisión y multa por haber infringido la Ley francesa sobre visitas comerciales a domicilio, debido a que el art. 4 de la citada Ley prohíbe a los comerciantes que realicen visitas a domicilio percibir pago alguno en metálico antes de que concluyera el plazo de siete días para desistir del contrato, norma que fue transgredida por el Sr. Pinto, debido a que los contratos que realizaba exigían

\footnotetext{
48 Cfr. Añoveros Terradas (2005), op.cit., p. 1740.

49 Cfr. HernándeZ FernándeZ (2006) en: http://www.consumo-inc.es/. [Con acceso el 12-XIIde-2010].

50 Vid. STJCE, Asunto C-361/89, Patrice di Pinto.

51 Vid. Durán Ayago (2008) p. 62
} 
el pago inmediato y además no mencionaban la posibilidad de renunciar a su compromiso antes de expirar el plazo de reflexión ${ }^{52}$.

No obstante, el Sr. Di Pinto apeló la sentencia condenatoria argumentando que los comerciantes que habían recibido las visitas no disfrutaban del régimen de protección, reservado a los consumidores; de lo contrario, la Ley francesa vulneraría lo previsto en la Directiva 85/577 sobre protección de los consumidores en el caso de contratos negociados fuera de los establecimientos comerciales ${ }^{53}$.

En el asunto que venimos comentando, el TJCE sostuvo que las personas jurídicas que actúen con fines de lucro no se les considera consumidores, por lo tanto, quedaban excluidas de la protección brindada por la hoy derogada Directiva 85/577/CE ${ }^{54}$. El criterio comentado se refleja en otras sentencias dictadas por el TJCE: asunto Ideal service vs. OMAl y otro (C-541-542/99), (sentencia del 19 de enero de 1993, Shearson Lehman Hutton, as. C-89/91), (sentencia Benincasa, as. C-269/95), entre otras.

Además, el TJCE ha dejado claro que resultan excluidos del ámbito de aplicación de las Directivas pro consummatore, los contratos celebrados sólo entre profesionales $(\mathrm{B} 2 \mathrm{~B})^{55}$. Asimismo, la normativa de protección de consumidores excluye de su ámbito de aplicación los contratos concluidos entre consumidores (C2C), lo cual se deduce de la lectura del artículo 2 TRLGDCU, el cual aclara: "Esta norma será de aplicación a las relaciones entre consumidores o usuarios y empresarios".

Una vez analizado el concepto de consumidor a nivel comunitario, pasaremos a ver qué ocurre a nivel nacional. En un inicio, la Ley 26/1984, del 19 de julio, General para la Defensa de los Consumidores y Usuarios ${ }^{56}$ (LGDCU) en su artículo 1.2, daba la siguiente definición de "consumidor":

\footnotetext{
52 Vid., ibídem.

53 Vid. Añoveros Terradas (2003) p. 100.

54 Vid. Durán Ayago, op.cit., p. 63.

55 Vid. STJCE de 21 de junio de 1978, Asunto C 150/77, Bertrand c. Paul Ott KG. Además, como acertadamente señala Romero García-Mora (2003) p. 144-145, quien Ilega a las siguientes dos conclusiones: "La primera y la más obvia que la noción de consumidor comunitario excluye de su contenido a las personas jurídicas; la segunda que por virtud del concepto de consumidor que se acoge resultarán excluidos del ámbito de aplicación de estas directivas pro consumatore los contratos que concluyan entre sí los profesionales y los que se concluyan entre consumidores".

56 BOE núm. 176, de 24-VII-1984.
} 
"A los efectos de esta Ley, son consumidores o usuarios las personas físicas o jurídicas que adquieren, utilizan o disfrutan como destinatarios finales, bienes muebles o inmuebles, productos, servicios, actividades o funciones, cualquiera que sea la naturaleza pública o privada, individual o colectiva de quienes los producen, facilitan, suministran o expiden". Por otra parte, en el mismo numeral, pero en su punto 3 aclaraba "no tendrán la consideración de consumidores o usuarios quienes sin constituirse en destinatarios finales, adquieran, almacenen, utilicen o consuman bienes o servicios, con el fin de integrarlos en procesos de producción, transformación, comercialización o prestación a terceros". De la lectura del artículo podemos señalar que se adaptaba a la normativa europea; y pese a que se incluía a las personas jurídicas, se hacía la siguiente aclaración: siempre y cuando éstas no compraran bienes o contrataran servicios con fines de lucro.

La Ley 43/2007, del 13 de diciembre, de protección de los consumidores en la contratación de bienes con oferta de restitución del precio ${ }^{57}$, da una definición de lo que es el consumidor o usuario en su artículo 1.3 cuando señala: "A los efectos de esta Ley, son consumidores o usuarios las personas físicas o jurídicas que adquieren, utilizan o disfrutan como destinatarios finales, bienes muebles o inmuebles, productos, servicios, actividades o funciones, cualquiera que sea la naturaleza pública o privada, individual o colectiva de quienes lo producen, facilitan, suministran o expiden". En nuestra opinión, esta Ley es acorde con lo dispuesto en el artículo 3 TRLGDCU, pues a pesar de no utilizar las mismas palabras y de incluir a las personas jurídicas, utiliza la siguiente expresión: "destinatarios finales", además en el mismo artículo 1.3, la norma comentada hace la siguiente aclaración: "No tendrán la consideración de consumidores o usuarios quienes sin constituirse en destinatarios finales, adquieran, almacenen, utilicen o consuman bienes o servicios, con el fin de integrarlos en procesos de producción, transformación, comercialización o prestación a terceros". De esta manera, aunque no se menciona la frase "sin fines de lucro", el concepto de consumidor brindado por la Ley 43/2007, encaja perfectamente con lo dispuesto en el artículo 3 TRLGDCU.

Otra de las normas que no utiliza propiamente el término consumidor sino "adherente", es el artículo 2 de la Ley 7/1998 de Condiciones Generales de la Contratación ${ }^{58}$. Sin embargo, tal y como apunta Fernández Gimeno, a pesar de que la Ley $7 / 98$ comprende tanto a las "personas físicas como jurídicas (con lo que incluye en la protección también a las sociedades de cualquier naturaleza) y que este profesional, en toda su extensión puede ser

57 BOE núm. 299, de 14-XII-2007.

58 BOE núm. 89 de 14-IV-1998. 
consumidor, siendo suficiente para que no quede excluido de la protección de la ley, que no actúe en el ámbito de su actividad y que sea destinatario final"59.

La DDC en su artículo 2.1 da una definición de "consumidor": "Toda persona física que, en contratos regulados por la presente Directiva, actúe con un propósito ajeno a su actividad comercial, empresa, oficio o profesión". En cambio, la Ley 3/2014, del 27 de marzo, por la que se modifica el Texto Refundido de la Ley General para la Defensa de los Consumidores y Usuarios y otras leyes complementarias, aprobado por el Real Decreto Legislativo $1 / 2007$, del 16 de noviembre ${ }^{60}$, por la que se transpone la DDC, modifica el concepto de consumidor estipulado en el artículo 3 TRLGDCU, el cual aclaramos se adapta a la normativa europea: "A efectos de esta norma y sin perjuicio de lo dispuesto expresamente en sus libros tercero y cuarto, son consumidores o usuarios las personas físicas que actúen con un propósito ajeno a su actividad comercial, empresarial, oficio o profesión. Son también consumidores a efectos de esta norma las personas jurídicas y las entidades sin personalidad jurídica que actúen sin ánimo de lucro en un ámbito ajeno a una actividad comercial o empresarial". Como puede verse, se menciona expresamente a las personas jurídicas como posibles "consumidores" ${ }^{\prime 61}$. En la línea de la citada jurisprudencia del TJCE ha de entenderse, como concluye la propia norma interna, que han de operar sin ánimo de lucro.

59 Vid. Fernández Gimeno, op.cit., pág. 104.

60 BOE núm. 76, de 28-III-2014.

61 Vid., Díaz Alabart y Álvarez Moreno., op.cit., p. 30, especialmente nota al pie núm. 22 cuando aclaran: "Un supuesto especial viene dado por las cooperativas de consumo que son aquellas que tienen por objeto el suministro de bienes o servicios adquiridos a terceros o producidos por ellas mismas, para uso y consumo de los socios y de quienes con ellos conviven, así como la educación, formación y defensa de los derechos de sus socios, en particular y usuarios en general (art. 88.1 Ley 27/1999 de 16 de julio de Cooperativas). Aunque este tipo de cooperativas realizan una actividad de comercialización dentro del mercado, la Disposición Adicional 5a, aptdos. 2o y 30 de dicha Ley dispone que: «las entregas de bienes y prestaciones de servicios proporcionadas por las sociedades cooperativas a sus socios, ya sean producidos por ellas o adquiridos a terceros para el cumplimiento de sus fines sociales no tendrán la consideración de ventas. Las cooperativas de consumidores y usuarios, las cooperativas agrarias y las cooperativas de transportistas, además de la condición de mayoristas, por lo que les serán de aplicación los precios a tarifas correspondientes, tendrán también, a todos los efectos, la condición de consumidores directos para abastecerse o suministrarse de terceros de productos o servicios que les sean necesarios para sus actividades». Por imperativo legal si se les considera consumidores, se debe sólo al deseo del legislador de favorecerlas". 
Por otra parte, anteriormente en la LGDCU de 1984 no se brindaba una definición de "empresario". Sin embargo, tal y como apunta la doctrina este concepto venía reconocido en diversas Directivas comunitarias en materia de protección de consumidor. Asimismo, a diferencia del concepto de consumidor, en donde la mayoría de las Directivas coinciden, a nivel comunitario no existe uniformidad en el empleo del término legal de empresario, ya que las normas que lo prevén lo nombran indistintamente, "empresario", "prestador de servicios", "vendedor", "detallista", etc. ${ }^{62}$.

De acuerdo con el artículo 4 TRLGDCU el empresario es: "toda persona física o jurídica, ya sea privada o pública, que actúe directamente o a través de otra persona en su nombre o siguiendo sus instrucciones, con un propósito relacionado con su actividad comercial, empresarial, oficio o profesión". Además, se incluyen dentro de este concepto, el productor, el proveedor, el comerciante, el fabricante, el importador, el suministrador, el organizador y detallista ${ }^{63}$. No obstante, como aclara Bercovitz Rodrícuez, "no basta con tener una actividad empresarial o profesional para que una persona quede sometida al ámbito de aplicación del Texto Refundido. Además el artículo 4 exige que la relación en cuestión entre consumidor y empresario se produzca precisamente en el marco de dicha actividad"64.

Por otro lado, la Ley no considera vendedores a los intermediarios proveedores en las compraventas entre particulares. No estamos de acuerdo con

62 Vid. Cámara Lapuente (2011), op.cit., pp. 155-156. [...]: "La disparidad, por lo demás, no trae su origen en traducciones inconsistentes, sino que también en la versión oficial de las Directivas en otros idiomas muestra esta heterogeneidad de designaciones para definir lo mismo (en el orden anterior, trader, supplier, seller, vendor, creditor o service provider). Desde una perspectiva nominalista, quizás convenga destacar que ninguna de las Directivas de consumo [...] utiliza la expresión "empresario" (business, excepción hecha de la fórmula objetivada por la Directiva 2000/35 de morosidad; y ni siquiera, en su versión inglesa, el concepto de "profesional", pues la Directiva 93/13 se refiere al seller or supplier).

${ }_{63}$ Cfr. Bercovitz Rodríguez-Cano (2009) pp. 101-103.

64 Ídem., pág. 103. 
tal postura, debido a que las grandes empresas como mercado libre ${ }^{65}$, ebay ${ }^{66}$, que realizan comercio electrónico, ganan anualmente cifras millonarias.

La problemática comentada se puso de manifiesto en el Libro Verde de Consumidores del año $2007^{67}$. En su punto 4.2, pregunta B2, se señalaba lo siguiente: “¿deberían considerarse los contratos entre particulares contratos de consumo cuando una de las partes actúa a través de un intermediario profesional?"

Opción 1: Statu quo: La protección de los consumidores no se aplicaría a los contratos entre los particulares cuando una de las partes recurra a un intermediario profesional para la celebración.

Opción 2: El concepto de contrato de consumo englobaría situaciones en las que una de las partes actúe a través de un intermediario profesional.

Sin embargo, la actual DDC se inclinó por la opción 1 y es la línea que sigue el artículo 2 TRLGDCU, tal y como vimos líneas arriba. En nuestra opinión una respuesta a la problemática planteada sería la integración de un "derecho de desistimiento" para este tipo de contratos, tal y como se contempla en el TRLGDCU (arts. 68-79), así como también el "régimen de garantías y servicios posventa" (arts. 123-127 TRLGDCU). De esta manera se le brindaría una mayor seguridad al consumidor que compre un bien o contrate un servicio por medio de un intermediario. De lo contrario se crea inseguridad jurídica.

65 Vid., punto 6.2, de las condiciones generales de Mercado Libre cuando aclara: "Dado que MercadoLibre es un punto de encuentro entre comprador y vendedor y no participa de las operaciones que se realizan entre ellos, el Vendedor será responsable por todas las obligaciones y cargas impositivas que correspondan por la venta de sus artículos, sin que pudiera imputársele a MercadoLibre algún tipo de responsabilidad por incumplimientos en tal sentido". Referencia tomada en: http://ayuda.mercadolibre.com.mx/ayuda/ terminos-y-condiciones-de-uso_991. [Con acceso el 20-IX-2015].

66 Vid., condiciones generales de ebay en el punto que habla sobre la responsabilidad cuando aclara: "Nosotros (incluyendo nuestra matriz, subsidiarias, filiales, administradores, agentes y empleados) no somos responsables frente a ti por responsabilidad contractual o extracontractual (incluyendo negligencia) o de cualquier otra forma, por cualquier pérdida de negocio y lucro cesante, tal como la pérdida de datos, beneficios, ingresos, negocios, oportunidades, fondo de comercio, reputación o la interrupción del negocio, o por las pérdidas que no sean razonablemente previsibles por nosotros que surjan, directa o indirectamente". Referencia tomada en: http://pages.ebay.es/help/policies/user-agreement.html?rt=nc\#buying_terms. [Con acceso el 20-IX-2015].

67 Libro Verde sobre la revisión del acervo en materia de consumo, COM (2006) 744 final, DOCE 15.3.2007, C 61/1, pág. 18 
Otro de los temas que cobra importancia con nuestro objeto de estudio es porqué a las Pequeñas y medianas empresas (en adelante PYMES) no se les considera consumidores, ya que para la doctrina las PYMES se encuentran en una condición de desigualdad a diferencia de las grandes empresas. En este sentido DurÁn AYAGO aclara: "La situación de debilidad en las relaciones contractuales hay que buscarla siempre en el principio de libertad contractual. Una libertad que sólo será real si existe cierta igualdad entre las partes. Si esa igualdad es real, no será necesario que el Derecho intervenga, pero si es meramente formal, entonces el Derecho deberá intervenir para garantizar que no se comentan abusos por parte de la empresa más fuerte. Y es que, como apuntaba ROUSSEAU, donde hay fuertes y débiles, la libertad oprime y la ley libera. No obstante, el concepto de debilidad es pluriforme. La debilidad puede derivarse de la asimetría informativa (contratos de consumo), de la carencia de libertad contractual del adherente cuando estemos ante contratos con condiciones generales o contratos de adhesión, o del desequilibrio económico que exista entre los contratantes que, qué duda cabe, puede derivar en un desequilibrio jurídico. Partiendo de este triple escenario, las pequeñas empresas, vitales para la economía, tanto española como europea, pero que sufren en muchos casos los riesgos de un comercio globalizado, son los actores principales de este trabajo, aunque en el escenario global no desempeñen más que un papel secundario. Con ellas como referencia hemos querido poner de manifiesto las carencias que se detectan en el actual régimen contractual internacional. Primero, porque se les despoja de la condición consumidores cuando consumen para su actividad profesional, aunque no sea en el ejercicio de su actividad profesional. Así, los textos comunitarios crean una esquizofrenia jurídica por diferenciar quiénes pueden ser considerados consumidores en contratos de consumo, cuando lo realmente interesante sería proteger a todas las personas que celebren un contrato de consumo ${ }^{68}$.

En este sentido no vemos problema alguno en considerar en un futuro a las PYMES como consumidores. De hecho la actual DDC deja abierta tal posibilidad, ello se deduce de la lectura del punto 13 de la norma comentada cuando aclara: "La aplicación de las disposiciones de esta Directiva a aspectos no incluidos en su ámbito de aplicación ha de seguir siendo competencia de los Estados miembros, con arreglo al Derecho de la Unión. De este modo, un Estado miembro podrá mantener o introducir normas de Derecho interno que correspondan a las disposiciones de la presente Directiva o a algunas de las disposiciones de la misma respecto de contratos que queden fuera del ámbito de aplicación de la presente Directiva. Por ejemplo, los Estados miembros podrán decidir extender la aplicación de lo dispuesto en la presente 
Directiva a las personas jurídicas o físicas que no sean «consumidores» en el sentido de la presente Directiva, como organizaciones no gubernamentales, empresas de reciente creación o pequeñas y medianas empresas [...]".

Sin embargo, en el ordenamiento jurídico español actualmente se excluye a las PYMES de la protección de consumidores, por lo tanto no pueden beneficiarse de ciertos beneficios como el derecho de desistimiento o el régimen de garantías y servicios posventa. No obstante, creemos que en un futuro no muy lejano, tanto el legislador europeo como español extenderán el régimen jurídico de protección del consumidor a las pequeñas y medianas y empresas, con el propósito de evitar a las grandes empresas, muchas de ellas con datos económicos que superan al producto interior bruto de muchos Estados. Estas empresas, cuando entran en relación con otras, de menor entidad económica, pueden tratar de imponer sus criterios en su propio y único beneficio, perjudicando a su co-contratante. De lo que se deduce que el desequilibrio económico presente cada vez con más frecuencia en las relaciones contractuales puede derivar en un desequilibrio jurídico. Al Derecho le corresponde corregir tal desajuste, favoreciendo a la parte débil de la relación ${ }^{69}$.

Hilando todo lo expuesto, Cámara Lapuente señala cómo el concepto de consumidor, el cual fue tan debatido a lo largo de dos décadas, ha llegado a uniformarse tanto a nivel comunitario como interno. Sin embargo, para este autor, tal concepto genera situaciones dudosas, las cuales no han sido resueltas ni contempladas en el ordenamiento jurídico, por ejemplo, los actos mixtos o adquisiciones para uso doble (personal y profesional), el concepto de consumidor activo o pasivo ${ }^{70}$, así como el problema del consumidor vendedor (C2B), o el consumidor representado por un profesional (C2C). Las hipótesis enunciadas plantean una serie de interrogantes, que deberían tomarse en consideración para evitar una serie de problemas que podrían presentarse en un futuro no muy lejano ${ }^{71}$.

De todo lo expuesto hasta el momento, nosotros brindamos el siguiente concepto de consumidor, el cual es acorde a la normativa europea y nacional: "es la persona física o jurídica que compra un bien o contrata un servicio destinándolos a un uso personal y sin fines de lucro".

69 Ibídem, nota anterior.

70 La diferencia entre consumidor activo y pasivo radica en que el primero es el que por su propia voluntad busca la compra de bienes o contratación de servicios y el segundo es a quien el empresario busca para la venta de productos o contratación de servicios.

71 Vid. Cámara Lapuente (2011 b), pp. 21 a 44. 


\section{CONCLUSIÓN}

El concepto de consumidor ha sido delimitado a nivel comunitario y nacional, en el sentido de excluirse a las personas físicas o jurídicas que adquieran bienes o contraten servicios con fines de lucro. Asimismo, el TJCE ha dejado claro qué debe entenderse por un contrato mixto en el asunto Engler. Sin embargo, existen todavía cuestiones por resolver, ya que no existe una postura firme; por ejemplo, en la normativa actual se excluyen del régimen de protección del consumidor la intermediación de los proveedores en las compraventas entre particulares, lo mismo ocurre con las PYMES.

No estamos de acuerdo con tal postura, pues como vimos en el primer caso existe una inseguridad jurídica al no existir responsabilidad alguna por parte de los intermediarios, ya que la normativa considera que existe una contratación entre particulares. En cambio, para en el caso de las PYMES hay un desequilibro contractual. Así, el Derecho debe intervenir para restablecer la situación de equilibrio perdida por los defectos del mercado y el Estado social debe intervenir allí donde las situaciones de desigualdad y desequilibrio no pueden ser corregidas simplemente con el uso de medidas de tipo económico. Cuestión distinta ocurre con el concepto de empresario, ya que dependiendo de la forma de conclusión del contrato en la que nos encontremos adquiere una connotación diferente: por ejemplo, detallista, prestamista, prestador de servicio, etc.

\section{BIBLIOGRAFÍA CITADA}

Añoveros Terradas, B. (2003): Los contratos de consumo intracomunitarios (Madrid, Marcial Pons).

AÑoveros Terradas, B. (2005): "Delimitación de los supuestos internacionales en los que se justifica el fórum actoris a favor del consumidor. (A propósito de las sentencias del TJCE en los asuntos Johann Gruber y Petra Engler)", La Ley, núm. 3, pp. 1737-1744.

Bercovitz Rodríguez-Cano, A. (1987): "Ámbito de aplicación y derechos de los consumidores", en Bercovitz/Bercovitz: Estudios jurídicos sobre protección de los consumidores (Madrid, Tecnos) pp. 328.

Bercovitz Rodríguez-Cano, R. (1992): "Comentario al artículo 1 de la Ley General para la Defensa de los Consumidores y Usuarios", en Bercovitz Rodríguez-Cano, Rodrigo y Salas Hernández, J., (Coords.): Comentarios a la Ley General para la Defensa de los Consumidores y Usuarios (Madrid, Civitas) 19-43 pp. 
Bercovitz Rodríguez-Cano, R. "El concepto de consumidor" (2005): en Azparren Lucas, A., (Dir.): Hacia un Código del consumidor (Manuales de Formación Continuada, núm. 34, Madrid) pp. 17-38.

Bercovitz Rodríguez-Cano, R. (2009): "Comentario al artículo 4 del TRLGDCU", en Bercovitz Rodríguez, C., (Coord.): Comentario del Texto Refundido de la Ley General para la Defensa de los Consumidores y Usuarios y otras leyes complementarias (Real Decreto Legislativo 1/2007), (Navarra, Aranzadi) pp. 99-103.

Botana García, G. A. (1994): Los contratos realizados fuera de los establecimientos mercantiles y la protección de los consumidores (Zaragoza J. M. Bosch Editor) pp. 324.

Cámara Lapuente, S. (2006): El control de las cláusulas "abusivas" sobre elementos esenciales del contrato (Navarra, Aranzadi) pp. 205.

Cámara Lapuente, S. (2011): "Comentarios a los artículos 1-7 del TRLGDCU", en Cámara Lapuente, S., (Dir.): Comentarios a las normas de protección de los consumidores: Texto Refundido (RDL 1/2007) y otras leyes y reglamentos vigentes en España y en la Unión Europea, (Madrid, Colex) pp. 77-203.

Cámara Lapuente, S. (2011 b): "El concepto legal de "consumidor en el Derecho Privado Europeo y en el Derecho español: aspectos controvertidos o no resueltos", Noticias de la Unión Europea (Monográfico, Derecho Privado Europeo), núm. 320, pp. 21-44.

Corchero Pérez, M y Grande Murillo, A. (2007): La protección de los consumidores, especial referencia al estatuto de consumidores de Extremadura (Navarra, Aranzadi).

Díaz Alabart, S y Álvarez Moreno T. (2014) "Comentario al artículo 2 de la DDC", en Díaz Alabart (Dir.): Contratos a distancia y contratos fuera del establecimiento mercantil (Madrid Reus) 21-80 pp.

DurÁn AYAGo, A. (2008): La protección de las PYMES en el comercio internacional: propuestas de regulación (Barcelona, Atelier).

Egusquiza Balmaseda, M. A. (2002): "Condiciones Generales y Comercio Electrónico", en Moro Almaraz, Ma. J. (Dir.): Internet y Comercio Electrónico (Salamanca, Universidad de Salamanca) pp. 17-34. 
EIDENMÜller et al (2012): "Hacia una revisión del acquis de consumo", en Cámara Lapuente, S (Dir.): La revisión de la normas europeas y nacionales de protección de los consumidores (Navarra, Civitas) pp. 107-162.

Esteban De La Rosa, F. (2003): La protección de los consumidores en el mercado interior europeo (Granada, Comares).

FeLIú Rey, M. I. (2009): “La nueva regulación europea de la figura del aprovechamiento por turno de bienes de adquisición de productos vacacionales de larga duración, de reventa y de intercambio: la Directiva 2008/122/ CEE", Derecho de los Negocios, núm. 122, pp. 19-27.

Fernández Gimeno, J. P. (2005): "Los consumidores y usuarios como sujetos afectos a una especial tutela jurídica", en Reyes López, M. J., (Coord.): Derecho privado de consumo (Valencia, Tirant lo Blanch) pp. 95-120.

García-Cruces González, J. A. (1989): "Derecho comunitario y Derecho del consumo", Revista de Derecho Mercantil, núm. 192, pp. 327-398.

Gómez Calero, J. (1994): Los derechos de los consumidores y usuarios (Madrid, Dykinson).

Gómez-Salvado Sánchez, C. (2008): "Las cláusulas de forma en las condiciones generales de la contratación. Panorama del Derecho Español", Revista de Derecho privado patrimonial, núm. 21, pp.135-148.

GonZález VAQUÉ L. (1999): "La noción de consumidor normalmente informado en la jurisprudencia del Tribunal de Justicia de las Comunidades Europeas: la Sentencia Gut Springenheide", Derecho de los Negocios, pp. 1-15.

GonZÁlez VAQuÉ L. (2005): “La noción de consumidor en el Derecho comunitario de consumo", Estudios sobre Consumo, núm. 75.

Hernández Fernández, A. (2006): "La protección del consumidor transfronterizo intracomunitario. Cuestiones de Derecho Internacional Privado", Estudios Sobre Consumo, núm. 79.

LASARTE Álvarez, C. (2007): Manual sobre protección de consumidores y usuarios (Madrid, Dykinson). 
Lete ACHiRICA, J. (1998): "La armonización de las legislaciones europeas sobre protección de los consumidores a la luz del derecho comunitario", Actualidad Civil, núm. 1, pp. 183-201.

Mangas Martín, A y Liñán Nogueras, D. J. (2010): Instituciones y Derecho de la Unión Europea (6 $6^{\mathrm{a}}$ ed., Madrid, Tecnos).

Martínez Espín, P. (2010): "Sobre el concepto de consumidor en materia de viajes combinados", en: www.uclm.es/cesco/pdf/comentarios/2.pdf. [Con acceso el 3-III-2010].

Munar Bernat, P. A. (1992): Presente y futuro de la multipropiedad (Madrid, Tecnos).

Ovalle Favela, J. (2005): "Los derechos de los consumidores", Revista de Derecho Privado Nueva Serie, núm. 12, pp. 75-111.

Reyes López, M. J. (2009): Manual de Derecho Privado de Consumo (Madrid, La Ley).

Romero García-Mora, G. (2003): Perspectivas para el consumidor ante el Derecho europeo de contratos (Madrid, Instituto Nacional del Consumo).

Ruiz-Rico Ruiz, M. J y García Alguacil, M. J. (2000): "Comentarios al artículo 1 de la ley de aprovechamiento por turnos", en Cañizares laso, A y Ruiz-Rico, J. M., (Dirs.): Multipropiedad y aprovechamiento por turno: Comentarios sistemáticos a la ley sobre derechos de aprovechamiento por turno (Madrid, Civitas) pp. 579.

Vicent Chulí́, F. (2004): "Condiciones generales de la contratación y condiciones abusivas bancarias", Revista de Derecho Privado Patrimonial, núm. 13, pp. 49-84.

\section{NORMAS JURÍDICAS CITADAS}

Acta Única Europea (DOCE no L 169, del 29 de junio de 1987). Disponible en:<http://europa.eu/legislation_summaries/institutional_affairs/treaties/ treaties_singleact_es.htm $>$, fecha de consulta: 10 de diciembre de 2009 .

Cumbre de París. Disponible en: <http://www.cepc.es/rap/Publicaciones/ Revistas>, fecha de consulta: 9 de noviembre de 2010. 
Directiva 2000/31/CE del Parlamento Europeo y del Consejo, del 8 de junio de 2000, relativa a determinados aspectos jurídicos de los servicios de la sociedad de la información, en particular el comercio electrónico en el mercado interior.

Directiva 2000/35/CE del Parlamento Europeo y del Consejo, 29 de junio de 2000, por la que se establecen medidas de lucha contra la morosidad en las operaciones.

Directiva 2002/22/CE del Parlamento Europeo y del Consejo, del 7 de marzo de 2002, relativa al servicio universal y los derechos de los usuarios en relación con las redes y los servicios de comunicaciones electrónicas.

Directiva 2002/65/CE del Parlamento Europeo y del Consejo, del 23 de septiembre de 2002, relativa a la comercialización a distancia de servicios financieros destinados a los consumidores, y por la que se modifican la Directiva 90/619/CEE del Consejo y las Directivas 97/7/CE y 98/27/CE.

Directiva 2002/83/CE del Parlamento Europeo y del Consejo, del 5 de noviembre de 2002, sobre el seguro de vida.

Directiva 2002/92/CE del Parlamento Europeo y del Consejo, del 9 de diciembre de 2002, sobre la mediación en los seguros.

Directiva 2003/6/CE del Parlamento Europeo y del Consejo, del 28 de enero de 2003, sobre las operaciones con información privilegiada y la manipulación del mercado (abuso del mercado).

Directiva 2003/71/CE del Parlamento Europeo y del Consejo, del 4 de noviembre de 2003, sobre el folleto que debe publicarse en caso de oferta pública o admisión a cotización de valores y por la que se modifica la Directiva 2001/34/CE.

Directiva 2004/39/CE del Parlamento Europeo y del Consejo, del 21 de abril de 2004, relativa a los mercados de instrumentos financieros, por la que se modifican las Directivas 85/611/CEE y 93/6/CEE del Consejo y la Directiva 2000/12/CE del Parlamento Europeo y del Consejo y se deroga la Directiva 93/22/CEE del Consejo.

Directiva 2005/29/CE del Parlamento Europeo y del Consejo, del 11 de mayo de 2005, relativa a las prácticas comerciales desleales de las empresas en sus relaciones con los consumidores en el mercado interior, que modifica las Directivas 84/450/CEE, 97/7/CE, 98/27/CE y 2002/65/CE, y el 
Reglamento (CE) n 2006/2004 (Directiva sobre las prácticas comerciales desleales).

Directiva 2006/114/CE del Parlamento Europeo y del Consejo, del 12 de diciembre de 2006, sobre publicidad engañosa y publicidad comparativa.

Directiva 2007/64/CE del Parlamento Europeo y del Consejo, del 13 de noviembre de 2007, sobre servicios de pago en el mercado interior, por la que se modifican las Directivas 97/7/CE, 2002/65/CE y 2006/48/CE y por la que se deroga la Directiva 97/5/CE.

Directiva 2007/65/CE del Parlamento Europeo y del Consejo, del 11 de diciembre de 2007, por la que se modifica la Directiva 89/552/CEE del Consejo sobre la coordinación de determinadas disposiciones legales, reglamentarias y administrativas de los Estados miembros relativas al ejercicio de actividades de radiodifusión televisiva.

Directiva 2008/48/CE del Parlamento Europeo y del Consejo, del 23 de abril de 2008, relativa a los contratos de crédito al consumo y por la que se deroga la Directiva 87/102/CEE del Consejo.

Directiva 2008/6/CE del Parlamento Europeo y del Consejo, del 20 de febrero de 2008, por la que se modifica la Directiva 97/67/CE en relación con la plena realización del mercado interior de servicios postales comunitarios.

Directiva 2009/72/CE del Parlamento Europeo y del Consejo, del 13 de julio de 2009, sobre normas comunes para el mercado interior de la electricidad y por la que se deroga la Directiva 2003/54/CE.

Directiva 93/13/CEE del Consejo, del 5 de abril de 1993, sobre las cláusulas abusivas en los contratos celebrados con consumidores.

Directiva 94/19/CE del Parlamento Europeo y del Consejo, del 30 de mayo de 1994, relativa a los sistemas de garantía de depósitos.

Directiva 97/7/CE del Parlamento Europeo y del Consejo del 20 de mayo de 1997, relativa a la protección de los consumidores en materia de contratos a distancia - Declaración del Consejo y del Parlamento Europeo sobre el apartado 1 del artículo 6 - Declaración de la Comisión sobre el primer guion del apartado 1 del artículo 3. 
Directiva 97/9/CE del Parlamento Europeo y del Consejo, del 3 de marzo de 1997, relativa a los sistemas de indemnización de los inversores.

Directiva de contratación a distancia COM (92), 11 final de 20 de mayo de 1992. Disponible en: <http://eur-lex.europa.eu/es/index.htm>, fecha de consulta: 14 de diciembre de 2009.

Directiva de publicidad engañosa, en: DOCE no L 376 de 27 de diciembre de 2006.

Directiva del Consejo 2000/43/CE, de 29 de junio de 2000, relativa a la aplicación del principio de igualdad de trato entre las personas independientemente de su origen racial o étnico.

Directive 2011/83/EU Of The European Parliament And Of The Council, of 25 October 2011, on consumer rights, amending Council Directive 93/13/ EEC and Directive 1999/44/EC of the European Parliament and of the Council and repealing Council Directive 85/577/EEC and Directive 97/7/ EC of the European Parliament and of the Council.

European Comission, Consumer affairs - Rights - General Contractual rights. Disponible en: <http://ec.europa.eu/consumers/rights/gen_rights_ en.htm\#uct>. Fecha de consulta: 9 de octubre de 2011.

Ley $n^{\circ}$ 26/1984, de 19 de julio, General para la Defensa de los Consumidores y Usuarios.

Ley $n^{\circ}$ 7/1998, de 13 de abril, sobre condiciones generales de la contratación.

Ley $n^{\circ} 43 / 2007$, del 13 de diciembre, de protección de los consumidores en la contratación de bienes con oferta de restitución del precio.

Texto Refundido de la Ley General para la Defensa de los Consumidores y Usuarios y otras leyes complementarias, aprobado por el Real Decreto Legislativo 1/2007, del 16 de noviembre.

Ley 29/2009, del 30 de diciembre, por la que se modifica el régimen legal de la competencia desleal y de la publicidad para la mejora de la protección de los consumidores y usuarios.

Ley 3/2014, del 27 de marzo, por la que se modifica el Texto Refundido de la Ley General para la Defensa de los Consumidores y Usuarios y 
otras leyes complementarias, aprobado por el Real Decreto Legislativo 1/2007, de 16 de noviembre.

Programa Preliminar (DOCE no C 092, de 25 de abril de 1975). Disponible en: $<$ http://eurlex.europa.eu/Notice.do?val=46469: cs\&lang=es\&list=464 69: cs, \&pos $=1 \&$ page $=1 \& \mathrm{nbl}=1 \&$ pgs $=10 \&$ hwords $=\&$ checktexte $=$ checkb ox\&vis=\#texte $>$. Fecha de consulta: 13 de noviembre de 2010.

Reglamento (CE) no 1371/2007 del Parlamento Europeo y del Consejo, de 23 de octubre de 2007, sobre los derechos y las obligaciones de los viajeros de ferrocarril.

Reglamento (CE) no 261/2004 del Parlamento Europeo y del Consejo, de 11 de febrero de 2004, por el que se establecen normas comunes sobre compensación y asistencia a los pasajeros aéreos en caso de denegación de embarque y de cancelación o gran retraso de los vuelos, y se deroga el Reglamento (CEE) n² 295/91.

Reglamento (CE) no 924/2009 del Parlamento Europeo y del Consejo, de 16 de septiembre de 2009, relativo a los pagos transfronterizos en la Comunidad y por el que se deroga el Reglamento (CE) n 2560/2001.

Tratado de Ámsterdam (DOCE no C 325, de 12 de diciembre de 2002, versión consolidada). Disponible en: <http://eurlex.europa.eu/es/treaties/ dat/11997D/htm/11997D.html>. Fecha de consulta: 10 de diciembre de 2010. Tratado de Roma. Disponible en:<http://www.historiasiglo20.org/ europa/traroma.htm>. Fecha de consulta: 10 de diciembre de 2010.

\section{JURISPRUDENCIA CITADA}

Supremo Tribunal de Justicia de la Comunidad Europea (STJCE), Francesco Benincasa contra Dentalkit (1997): 3 de julio de 1997, Asunto C-269/95. Disponible en: <http://eur-lex.europa.eu/legal-content/ES/TXT/HTML/?ur $\mathrm{i}=$ CELEX:61995CJ0269\&from=ES $>$, fecha de consulta: 29 de octubre de 2014.

Supremo Tribunal de Justicia de la Comunidad Europea (STJCE), Shearson Lehman Hutton Inc. v. TVB Treuhandgesellschaft für Vermögensverwaltung und Beteiligungen mbH (1993): 19 de enero de 1993, Asunto C-89/91. Disponible en: <http://eur-lex.europa.eu/legalcontent/ES/TXT/PDF/?uri= OJ:JOC_1993_035_R_0005_03\&qid=1414636484565\&from $=E N>$, fecha de consulta: 29 de octubre de 2014. 
Supremo Tribunal de Justicia de la Comunidad Europea (STJCE), Petra Engler contra Janus Versand GmbH (2005): 20 enero 2005, Asunto C-27/02. Disponible en: <http://eur-lex.europa.eu/legal-content/ES/TXT/PDF/?uri= CELEX:62002CJ0027\&rid=1 >, fecha de consulta: 29 de octubre de 2014.

Supremo Tribunal de Justicia de la Comunidad Europea (STJCE), Johann Gruber contra Bay Wa Ag (2005) 20 de enero de 2005, Asunto C-464/01. Disponible en: <http://eur-lex.europa.eu/legal-content/ES/TXT/PDF/?uri= CELEX:62001CJ0464\&qid=1414637219424\&fr om=ES>, fecha de consulta: 29 de octubre de 2014. 
